\title{
Commonplace
}

\section{Preparing Students for Wicked Problems}

\section{Karen Ciccone}

Published on: Feb 24, 2022

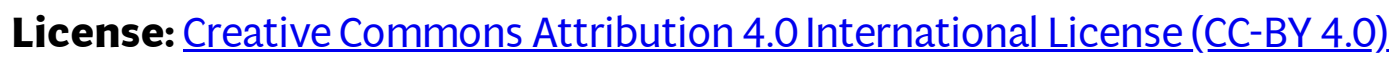


We live in a world that's filled with problems, and big ones at that. From pandemics, to food scarcity, to climate change, there is a lot of chaos that we're grappling with and trying to identify solutions. Especially college students are struck by the world's big problems as they come into adulthood and identify their own place, identities, and careers in this messy world. Wicked Problems, Wolfpack Solutions is a small part in bridging that gap between college and facing real-world problems. A course based out of North Carolina State University, this online class connects incoming students with instructors and researchers to develop skills to prepare them for the ever-changing world. This conversation with Karen Ciccone, Lead Librarian for Public Science at NC State, highlights the motivations behind the course.

What was the motivation for "Wicked Problems, Wolfpack Solutions"?

The Wicked Problems, Wolfpack Solutions online course was first offered during the summer of 2020, when the COVID pandemic made it necessary to move courses and new student orientations online. It was designed to get students excited about coming to NC State by showcasing some of the amazing work being done by NC State scholars in a wide variety of disciplines. It was also intended to help students develop skills they would need for college and to introduce them to ways they can get involved through research, service, study abroad, student organizations, and further learning. The course is offered each year to all incoming first-year and transfer students and their families. Our hope is that it will alter how students feel about the meaningful work they can achieve at NC State and about the value of bringing interdisciplinary perspectives to that work.

How do you choose what the curriculum is?

Each year, the course focuses on a particular "wicked problem," which is a highly complex problem that can only be addressed through collaborative, multidisciplinary efforts. The theme of the course that first summer was an obvious choice-Pandemics. For the second iteration of the course, in the summer of 2021, we focused on another urgent wicked problem-Global Change. The upcoming course will consider wicked problems related to the Future of Food, including not only how to produce more food to meet our growing global population, but how to do so in ways that are just and sustainable. NC State's motto is "Think and Do," and each version of the course explores possible solutions to wicked problems through the perspectives of NC State scholars representing many different areas of study. The curriculum also reflects NC 
State's commitment to the inclusion of individuals and ideas from a broad diversity of backgrounds and experiences.

Who was selected to create podcasts and videos for the curricula?

Our goal is to feature outstanding talks by some of NC State's best scholar communicators. Because the course is intended to help students explore how different disciplines each offer valuable, evidence-based perspectives and solutions to the wicked problems of the world, we aim to feature faculty from all of NC State's colleges and as many different departments as possible.

Why and how did you set up this class-room structure? What has the implementation been like?

The course is made available to students in WolfWare-NC State's suite of academic technologies-giving students experience with the technologies they'll use during their academic careers before they begin their first semester at NC State. The course includes both asynchronous and synchronous components-not only recorded presentations but also reflections, project assignments, and opportunities for live interactions with the course instructors. It takes a large team of people to bring an online experience like this to life. Melissa Ramirez and Jason Flores are the instructors and make the final decisions about course design.

Because of the high quality and relevance of the faculty presentations, we also wanted to make them more widely available. We used PubPub to create an open version of the course that we could share with other educators, prospective students, their families, alumni, and the general public as both an educational resource and a showcase of NC State work. We chose this platform because of its clean and attractive appearance, the amount of control we have over organization, and the ability to issue DOIs for each of the presentations.

How have you encouraged students to take - and engage with - this class?

The course focuses on topics that are highly relevant to the daily lives of students and their families. It is offered for free to all incoming first-year and transfer students, who are automatically enrolled in the course. In order to receive credit on their transcripts, students must complete the course activities and project assignments. However, the grading is pass/fail, and there are multiple ways to pass and very few ways to fail. Families are invited to watch the videos with their students. We encourage students to engage with and complete the course through various forms of communication as part of their new student onboarding. 
What has been the experience in the classes so far? what does the metric of success look like for you?

Student feedback on the Wicked Problems, Wolfpack Solutions experience has been overwhelmingly positive. Students have said that the course has helped them realize that, regardless of their major, they can contribute to finding solutions to global problems. They have also said that the course has helped them explore different subject areas, and it has caused some to consider changing their area of study or adding a minor. The complexity of the problems we face, and the wide range of disciplines involved in improving the world, has been surprising to many. The student reflections and post-course feedback provide qualitative evidence that the course helps students understand the value of interdisciplinarity and envision the contributions they themselves can make to solving wicked problems. That's the major measure of success for us.

Any advice or tips to give to other educators in creating engaging, hopeful, helpful, and educational learning experiences online?

I asked this question of one of the course instructors, Jason Flores. He said, "Knowing your student population is very important and will help guide what to include and what to ask of them during this course. Our population of highly motivated students are still mostly 17- and 18-year-olds, fresh out of high school, in the middle of their last free summer, but also excited about their future university as well as their personal futures. It's a great time to get them engaged but we also have to be careful not to overwhelm them. I would also say that having a wide variety of content is as important as having a wide variety of delivery methods (synchronous, asynchronous, small groups, larger groups, podcasts, videos, interviews, lectures, etc.), as well as the involvement of many different campus partners (libraries, clubs, living communities, etc.)."

My role in this project is mainly focused on finding ways for other instructors and campus programs to connect to and build upon the course, and on creating the open version to facilitate reuse of the course materials. We plan to share the open version widely and hope that people will find the presentations engaging and enlightening, and that other educators will find them to be useful supplements to their own instruction.

Keep the conversation going:

How else can we prepare the next generation to think critically and solve big issues? 
What programs (online or otherwise) have you seen/been involved in that put education ownership into the hands of students? 